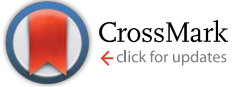

Cite this: Chem. Sci., 2015, 6, 5230

\title{
A soluble molecular variant of the semiconducting silicondiselenide $\uparrow$
}

\author{
Kartik Chandra Mondal, ${ }^{a}$ Sudipta Roy, ${ }^{a}$ Birger Dittrich, ${ }^{\text {bb }}$ Bholanath Maity, ${ }^{\mathrm{c}}$ \\ Sayan Dutta, ${ }^{c}$ Debasis Koley, ${ }^{* c}$ Suresh Kumar Vasa, ${ }^{d}$ Rasmus Linser, ${ }^{d}$ \\ Sebastian Dechert ${ }^{a}$ and Herbert W. Roesky ${ }^{\star a}$
}

Silicondiselenide is a semiconductor and exists as an insoluble polymer $\left(\mathrm{SiSe}_{2}\right)_{n}$ which is prepared by reacting elemental silicon with selenium powder in the temperature range of $400-850{ }^{\circ} \mathrm{C}$. Herein, we report on the synthesis, isolation, and characterization of carbene stabilized molecular silicondiselenide in the form of $(\mathrm{CAAC})_{2} \mathrm{Si}_{2} \mathrm{Se}_{4}$ (3) [CAAC = cyclic alkyl(amino)carbene]. 3 is synthesized via reaction of diatomic silicon(0) compound $(\mathrm{CAAC})_{2} \mathrm{Si}_{2}$ (2) with black selenium powder at $-78{ }^{\circ} \mathrm{C}$ to room temperature. The intensely orange colored compound 3 is soluble in polar organic solvents and stable at room temperature for a month under an inert atmosphere. 3 decomposes above $245^{\circ} \mathrm{C}$. The molecular structure of 3 has been confirmed by X-ray single crystal diffraction. It is also characterized by UV-vis, IR, Raman spectroscopy and mass spectrometry. The stability, bonding, and electron density distributions of 3 have been studied by theoretical calculations.

Received 25th April 2015

Accepted 17th June 2015

DOI: $10.1039 / \mathrm{c} 5 \mathrm{sc} 01516 \mathrm{~b}$

www.rsc.org/chemicalscience

Several modified synthesis routes have been developed in

\section{Introduction}

The synthesis of silicon diselenide ( $\mathrm{SiSe}_{2} ; \mathbf{A}$ in Scheme 1) was first reported by P. Sabatier in $1891 .^{1}$ Six decades later crystalline $\mathrm{SiSe}_{2}$ was prepared by Weiss et al. ${ }^{2}$ who reported the Bravais lattice of the crystal structure of $\mathrm{SiSe}_{2}$ as body-centered orthorhombic. Structural analysis showed that it crystallizes in space group Ibam. ${ }^{3 a-b} \mathrm{SiSe}_{2}$ has a unique crystalline structure which consists of infinite nonintersecting chains of edge-sharing tetrahedra (A) as shown in Scheme $1 .^{3 a-b}$ The structural scenario of amorphous $\mathrm{SiSe}_{2}$ is more complicated, ${ }^{3 c}$ where the Si atoms are linked via intra- and inter-tetrahedral bonds connected by Se atoms. The predominant structural motif of amorphous $\mathrm{SiSe}_{2}$ follows the sequence involving both corner- and edgesharing connections, ${ }^{3 c}$ which are importantly more frequent than those constructed exclusively by edge-sharing Si atoms in crystalline $\mathrm{SiSe}_{2} \cdot{ }^{3 \boldsymbol{a}-\boldsymbol{b}}$

${ }^{a}$ Institut für Anorganische Chemie, Georg-August-Universität, 37077 Göttingen, Germany.E-mail: hroesky@gwdg.de

${ }^{b}$ Institut für Anorganische und Angewandte Chemie, Universität Hamburg, 20146 Hamburg, Germany, Raum AC 15c (Erdgeschoss)

${ }^{c}$ Dept. of Chemical Sciences, Indian Institute of Science Education and Research (IISER) Kolkata, Mohanpur-741246, India

${ }^{d}$ Max-Planck-Institut für Biophysikalische Chemie, Abtl. NMR-basierte Strukturbiologie, 37077 Göttingen, Germany

† Electronic supplementary information (ESI) available: Syntheses, NMR, UV-vis, Raman spectra, crystallographic table, and theoretical details. CCDC 926618, 927696, 948799, 983863, 1060365. For ESI and crystallographic data in CIF or other electronic format see DOI: $10.1039 / \mathrm{c} 5 \mathrm{sc} 01516 \mathrm{~b}$ quest of the physical properties of $\mathrm{SiSe}_{2}$ in a single phase. Large red rods of $\mathrm{SiSe}_{2}$ have been grown for 4-7 days inside a quartz tube at $1000{ }^{\circ} \mathrm{C}$ under high vacuum placed in a furnace. ${ }^{\mathbf{4 - 6}}$ They are highly moisture sensitive and undergo hydrolysis on the surface to produce silicon- and selenium dioxide. ${ }^{4}$ The glass transition temperature and crystallization temperature of $\mathrm{SiSe}_{2}$ are 460 and $610{ }^{\circ} \mathrm{C}$, respectively. ${ }^{5}$ Further studies showed that $\mathrm{SiSe}_{2}$ can exist as three different polymorphs depending upon the temperature $\left(400-850{ }^{\circ} \mathrm{C}\right)$ of preparation. ${ }^{6}$ Crystalline $\mathrm{SiSe}_{2}$ is considered to be a semiconductor ${ }^{4,7 \boldsymbol{a}-\boldsymbol{b}}$ and has a huge potential to be used in solar cells. ${ }^{7 c}$

After the first synthesis report of $\mathrm{N}$-heterocyclic carbenes (NHCs) in 1991, they have been utilized as strong $\sigma$-donating ligands in different areas of chemistry. ${ }^{8}$ The mono-atomic and diatomic variants of silicon are stabilized by NHCs and cAACs in form of $\mathrm{L}: \rightarrow \mathrm{Si}(0)=\mathrm{Si}(0) \leftarrow: \mathrm{L}$, and $\mathrm{L}: \rightarrow \mathrm{Si}(0) \leftarrow: \mathrm{L}[\mathrm{L}:=\mathrm{NHC}$ or cAAC (cyclic alkyl(amino)carbene)]. ${ }^{9,10}$ Several variants of phosphorus are stabilized by NHCs and cAACs, respectively. ${ }^{\mathbf{1 0 , 1 1}}$ G. Bertrand et al. have stated ${ }^{\mathbf{1 0}}$ that carbene stabilized variants of these elements are synthesized not only for academic curiosity but also for their solubility in organic solvents. Since organic ligand-anchored variants are more soluble in organic

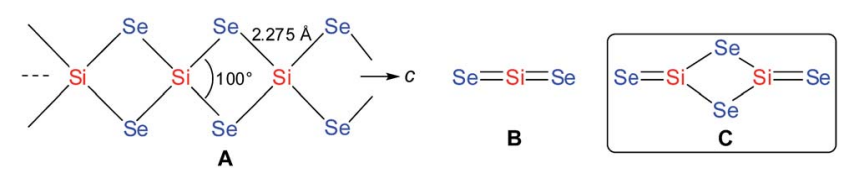

Scheme 1 Schematic representation of some forms of $\mathrm{SiSe}_{2}$. 


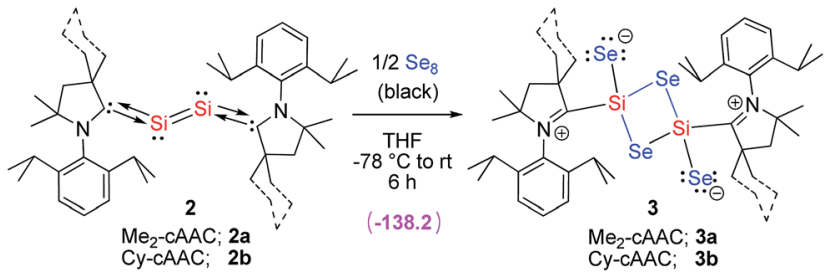

Scheme 2 Synthesis of compound 3 from 2. The energy term in parenthesis is $\Delta G\left(\mathrm{kcal} \mathrm{mol}^{-1}\right)$ at M06-2X/TZVP/SMD//M06-2X/SVP level of theory for $2 \mathrm{a}$ to $3 a$.

solvents, their chemical transformations are much easier and faster. They are suggested to be utilized for the synthesis of the smaller units of the larger framework/polymer such as silicon dioxide $\left(\mathrm{Si}_{2} \mathrm{O}_{4}\right){ }^{10}$ Very recently, the syntheses and characterizations of $(\mathrm{NHC})_{2} \mathrm{Si}_{2} \mathrm{O}_{3}$ and $(\mathrm{NHC})_{2} \mathrm{Si}_{2} \mathrm{O}_{4}$ were reported by Robinson et al. ${ }^{12 a}$ Reaction of $(\mathrm{NHC})_{2} \mathrm{Si}_{2}$ with excess of oxygen donor $\left(\mathrm{N}_{2} \mathrm{O}\right.$ or $\left.\mathrm{O}_{2}\right)$ led to the isolation of free $\mathrm{NHC}$ and uncharacterized decomposed product of silicon oxide. The light yellow colored $(\mathrm{NHC})_{2} \mathrm{Si}_{2} \mathrm{O}_{3}$ was isolated only when three equivalents of $\mathrm{N}_{2} \mathrm{O}$ are allowed to react with $(\mathrm{NHC})_{2} \mathrm{Si}_{2}$. Note, that $(\mathrm{NHC})_{2} \mathrm{Si}_{2} \mathrm{O}_{3}$ does not convert to higher oxide analogue (NHC) $)_{2} \mathrm{Si}_{2} \mathrm{O}_{4}$ when the former compound is further reacted with $\mathrm{N}_{2} \mathrm{O}$. The synthesis of colorless compound ( $\left.\mathrm{NHC}\right)_{2} \mathrm{Si}_{2} \mathrm{O}_{4}$ is successful only when $(\mathrm{NHC})_{2} \mathrm{Si}_{2}$ is reacted with two equivalents of molecular oxygen $\left(\mathrm{O}_{2}\right){ }^{12 a} \mathrm{Y}$. Apeloig has summarized the compounds containing $\mathrm{Si}=\mathrm{O}$ double bonds giving high emphases on NHC stabilized $\mathrm{Si}_{2} \mathrm{O}_{3}$ and $\mathrm{Si}_{2} \mathrm{O}_{4}$ oxides. ${ }^{12 b}$ However, monomeric or dimeric variants of $\operatorname{SiSe}_{2}$ (B, C; Scheme 1) in the molecular form are even not reported by low temperature matrix-isolation. Herein, we report on the synthesis and characterization of carbene-stabilized $\left(\mathrm{SiSe}_{2}\right)_{2}$ in the molecular form of (cAAC) $)_{2} \mathrm{Si}_{2} \mathrm{Se}_{4}$ (3). The reaction employed cAAC-supported diatomic silicon(0) (cAAC) $)_{2} \mathrm{Si}_{2}$ (2) which is reacted with black selenium powder in the temperature range of $-78{ }^{\circ} \mathrm{C}$ to $\mathrm{rt}$ (Scheme 2). Moreover, the stability and bonding of 3 are studied by theoretical calculations.

\section{Result and discussion}

Both cAAC and NHC form stable adducts with $\mathrm{SiCl}_{4}{ }^{9 a, c}$ The colorless adducts (cAAC) $\rightarrow \mathrm{SiCl}_{4}\left(\mathbf{1} \mathbf{a}, \mathrm{Me}_{2}\right.$-cAAC; $\mathbf{1 b}, \mathrm{Cy}$-cAAC) are obtained when cAACs react with $\mathrm{SiCl}_{4}$ in $1: 1$ molar ratio in THF. ${ }^{15 a, 9 c}$ The diatomic silicon(0) (cAAC) $)_{2} \mathrm{Si}_{2}(\mathbf{2 a}-\mathbf{b})$ has been synthesized by complete dechlorination of $\mathbf{1}$ with four equiv of $\mathrm{KC}_{8}$ in THF (see ESI $\dagger$ ). 2a-b are isolated as dark black-purple needles from $n$-hexane solution (see ESI for details, Schemes $\mathrm{S} 1-\mathrm{S} 2 \dagger)$. The yield of $2 \mathrm{a}$ is $52 \%$ which is higher than that of red colored ( $\mathrm{NHC})_{2} \mathrm{Si}_{2}(21 \%)^{9 a}$ but comparable to that of $2 \mathbf{b b}^{9 c}$ Theoretical calculation showed that cAAC is more firmly bound to the $\mathrm{Si}_{2}$ unit and thus 2 is even characterized by EI-mass spectrometry, ${ }^{9 c}$ while its $\mathrm{NHC}$ analogue $(\mathrm{NHC})_{2} \mathrm{Si}_{2}$ is not. The latter species dissociates under such conditions and only free NHC is found in the mass spectrum. This is due to the weaker $\pi$ accepting property ${ }^{13}$ which makes NHC-containing compounds more labile. ${ }^{14}$
$(\mathrm{NHC})_{2} \mathrm{Si}_{2},{ }^{9 a}$ and $(\mathrm{cAAC})_{2} \mathrm{Si}_{2}$ (2a, $\mathrm{Me}_{2}$-cAAC; $\left.2 \mathbf{b}, \mathrm{Cy}-\mathrm{cAAC}\right)$ are studied by solid state ${ }^{29} \mathrm{Si}$ NMR at room temperature (rt) to compare the electronic environments of the silicon atoms. (NHC) $)_{2} \mathrm{Si}_{2}$ shows its ${ }^{29} \mathrm{Si}$ resonance at 202.4-204.3 ppm which is close to the corresponding value of $224.5 \mathrm{ppm}$ (singlet) in solution. ${ }^{9 a}$ Analogous measurement on 2a exhibits a singlet at $254.6 \mathrm{ppm}$, while two resonances (190.1 and $318.3 \mathrm{ppm}$ ) are observed for $\mathbf{2 b}$. Note, that the calculated [(190.1+318.3)/2= $254.2]$ mean value is $\sim 254 \mathrm{ppm}$. There is no resonance around $254 \mathrm{ppm}$ in the solid state ${ }^{29} \mathrm{Si}$ NMR of $2 \mathbf{b}$ suggesting that the two silicon atoms are not equivalent. The changes in the chemical shift values of NHC and cAAC derivatives are attributed to the higher $\pi$-accepting property of cAAC over NHC. ${ }^{16}$ However, the reason behind the two well separated (128.2 ppm) ${ }^{29} \mathrm{Si}$ resonances in $\mathbf{2 b}$ is not apparently understood. The temperature dependent X-ray single crystal studies revealed that both $\mathbf{2 a}$ and $\mathbf{2 b}$ crystallize in the triclinic $P \overline{\mathbf{1}}$ space group. The center of inversion in between the two silicon atoms in $\mathbf{2 b}$ is absent at $100 \mathrm{~K}$ (see ESI $\dagger$ ), but it is present at $23 \mathrm{~K}^{9 c}$ In comparison, the center of inversion in between the two silicon atoms in $2 \mathrm{a}$ is present even at $100 \mathrm{~K}$ (see ESI $\dagger$ ). Structural comparison between $\mathbf{2 a}$ and $\mathbf{2 b}$ clearly shows that the carbene moieties are evenly disordered in $\mathbf{2 a}$ but not in $\mathbf{2 b}$ (Fig. S5-S8†). The combined solid state NMR and temperature dependent Xray structural correlation unambiguously clarify the acute differences of electronic environments of silicon atoms in $\mathbf{2 a - b}$. In the solution phase both $\mathbf{2} \mathbf{a}$ and $\mathbf{2 b}$ have a similar coordination environment and hence their ${ }^{29} \mathrm{Si}$ resonances are close to each other (252.3 ppm for $\mathbf{2 a}$ and $249.1 \mathrm{ppm}$ for $\mathbf{2 b}$ ) (Schemes S5-S6, Fig. S12-S13, see ESI $\dagger$ for details).

Compound 2 is dissolved in THF to obtain a dark purple solution which is cooled to $-78{ }^{\circ} \mathrm{C}$ and passed into another flask containing black selenium powder $(2: \mathrm{Se}=1: 4$ molar ratio). A light green color is obtained after stirring the solution for ten minutes. The green color of the solution is becoming more intense when stirring is continued for twenty minutes. Then the mixture is stirred for $3 \mathrm{~h}$ to obtain a brown solution with unreacted selenium powder. Stirring is continued for another $2.5 \mathrm{~h}$ to produce a clear orange solution. The volume of the THF solution is reduced to $2 \mathrm{~mL}$ under vacuum. Finally, 3 $\mathrm{mL}$ of toluene are added and the orange solution is stored at $-32{ }^{\circ} \mathrm{C}$ in a freezer to form small orange blocks/needles of 3 in $30-32 \%$ yield. Compound $\mathbf{3 b}$ is comparatively more soluble in THF than 3a. Very recently the synthesis and isolation of $(\mathrm{NHC})_{2} \mathrm{Si}_{2} \mathrm{O}_{3}$ and $(\mathrm{NHC})_{2} \mathrm{Si}_{2} \mathrm{O}_{4}$ were reported by reacting (NHC) $)_{2} \mathrm{Si}$ with $\mathrm{N}_{2} \mathrm{O}$ and $\mathrm{O}_{2}$, respectively. ${ }^{12}$ The formation of $(\mathrm{NHC})_{2} \mathrm{Si}_{2} \mathrm{O}_{3}$ and $(\mathrm{NHC})_{2} \mathrm{Si}_{2} \mathrm{O}_{4}$ depends on the source of oxygen. Importantly, when (NHC) ${ }_{2} \mathrm{Si}_{2} \mathrm{O}_{3}$ was further reacted with $\mathrm{N}_{2} \mathrm{O}$ led to the isolation of decomposed by-products and thus $(\mathrm{NHC})_{2} \mathrm{Si}_{2} \mathrm{O}_{4}$ was not obtained. It is well known that NHC mostly favors the formation of coordinate $\sigma$-bonds while cAAC forms both coordinate and electron sharing covalent $\sigma$-bonds depending on the electronic situation of the involved silicon atom. ${ }^{15}$

We have carried out the reaction of $2 \mathrm{a}$ and Se-powder in $1: 2$, $1: 3$, and $1: 4$ molar ratios. The reaction in a $1: 2$ molar ratio does not produce the green intermediate color. A dark brown 
solution was obtained. The solvent was removed and the dry residue was extracted with $n$-hexane to obtain a brown filtrate and crystalline $3 \mathrm{a}$ in $\mathbf{1 0}-\mathbf{1 2} \%$ yield. The concentrated $n$-hexane solution was stored at $-32{ }^{\circ} \mathrm{C}$ in a freezer. No crystals were formed. The removal of solvent ( $n$-hexane) produced an oily material. The reaction in a $1: 3$ molar ratio proceeds first to a lighter green intermediate color. In the following step a lighter orange solution was obtained from which the crystalline powder of 3a was isolated in 17-20\% yield.

The crystals of $\mathbf{3 a - b}$ are stable in air for several days and retain their dark orange color for a week while THF solutions of 3a-b slowly loose their color when exposed to air. Orange powders of $3 \mathbf{a}-\mathbf{b}$ decompose above $285{ }^{\circ} \mathrm{C}(3 \mathbf{a}), 245{ }^{\circ} \mathrm{C}(3 \mathbf{b})$ to give light yellow solids of $\mathrm{CAAC}=\mathrm{Se} .{ }^{17}$ This is concluded from mass spectrometry (see ESI $\dagger$ ). Compound 3a was further characterized by EI-MS mass spectrometry $(\mathrm{m} / \mathrm{z}$ (100\%); 944.2) (see ESI $\dagger$ ). The UV-vis spectra of compounds $\mathbf{3 a} \mathbf{a}-\mathbf{b}$ recorded in THF solution show absorption bands at $422 \mathrm{~nm}$ (3a) and $402 \mathrm{~nm}$ (3b), respectively (see ESI $\dagger$ ) which are close to the values obtained from theoretical TD-DFT calculation (400-440 nm; Tables S10 and S11 $\dagger$ ). Relative transitions are explained from KS-MO of 3a shown in Fig. S15. $\dagger$ The infrared (IR) spectrum of 3a (measured in the range of 400-4000 $\mathrm{cm}^{-1}$ ) showed a sharp absorption band at $547 \mathrm{~cm}^{-1}$. It is close to the theoretically calculated values of $533.3 \mathrm{~cm}^{-1}\left(\nu_{\mathrm{Si}=\mathrm{Se}}\right)$ and $355.1 \mathrm{~cm}^{-1}\left(\nu_{\mathrm{Si}-\mathrm{Se}}\right)$ of 3a. Additionally, 3a is investigated by Raman spectroscopy (see ESI $\dagger$ ). Raman spectra are recorded on solid sample of $\mathbf{3 a}$ which exhibit Raman bands at $1490.9 \mathrm{~cm}^{-1}$ and $1475.9 \mathrm{~cm}^{-1}$ with a shoulder. A strong Raman band $\left(\nu_{\mathrm{Si}=\mathrm{Si}}\right)^{9 c}$ was observed at $478 \mathrm{~cm}^{-1}$ for (cAAC) $)_{2} \mathrm{Si}_{2}$ which is not present in 3a. Both the compounds $\mathbf{3 a - b}$ are studied by solution and solid state NMR measurements. ${ }^{1} \mathrm{H}$ and ${ }^{13} \mathrm{C}$ NMR resonances are very broad and hence not much informative (Fig. S11 $\dagger$ ). ${ }^{29} \mathrm{Si}$ and ${ }^{77} \mathrm{Se}$ NMR resonances are not observed. The zwitterionic nature (Schemes 2 and 3) of compound 3 might be the reason for the broadening of the NMR resonances. However, the corresponding chemical shift values of carbene carbon, silicon, and selenium atoms are theoretically calculated and given in the ESI. $\dagger$

Structural descriptions of $\mathbf{2 a - b}$ are given in ESI. $\uparrow$ Compound 3a crystallizes in the space group $P 2_{1} / n$ and possesses a center of inversion within the molecule. The asymmetric unit of $\mathbf{3 a}$ contains the $\left(\mathrm{Me}_{2}-\mathrm{cAAC}\right) \mathrm{SiSe}_{2}$ fragment. The complete molecular structure of $\mathbf{3 a}$ generated from applying inversion symmetry is shown in Fig. 1.

The $\mathrm{Se}=\mathrm{Si}\left(\mu\right.$-Se) ${ }_{2} \mathrm{Si}=$ Se unit (alike $\mathbf{C}$ shown in Scheme 1 ) is coordinated by two $\mathrm{Me}_{2}$-cAAC ligands. Both silicon atoms adopt a four coordinate distorted tetrahedral geometry. The $\mathrm{C}_{\mathrm{CAAC}}-\mathrm{Si}$

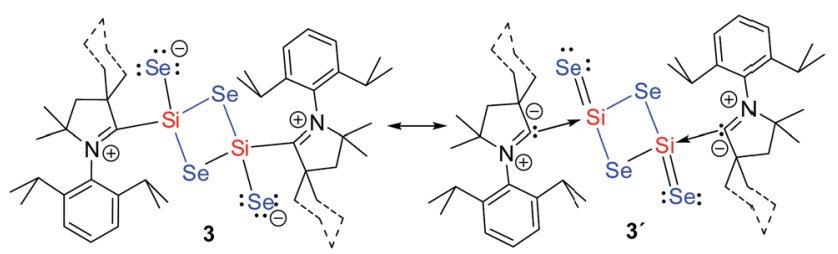

Scheme 3 Resonance structures of compound 3.
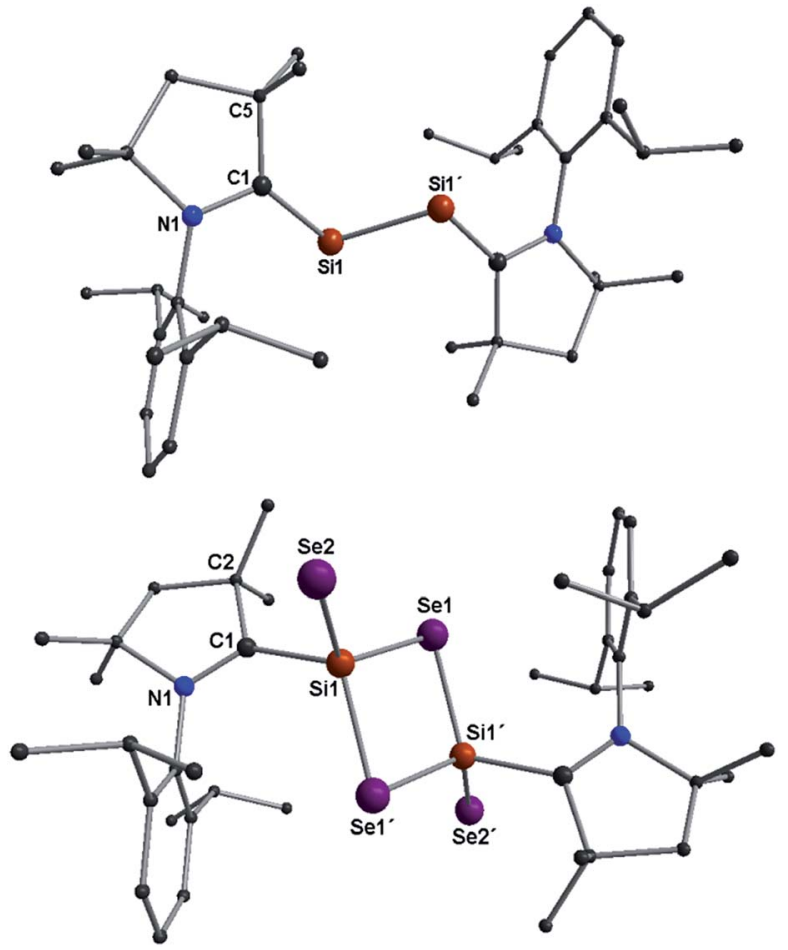

Fig. 1 Molecular structures of compounds 2a (top), 3a (bottom). H atoms are omitted for clarity. Selected experimental [calculated at RM06-2X/SVP for the singlet state] bond lengths $[\AA]$ and angles $\left[{ }^{\circ}\right]$ (as averages of two independent molecules): for 2a/3a; C1-Si1A 1.887(4)/ 1.931(4) [1.877/1.947], Si1A-Si1A' 2.254(2)/3.056 [2.244/3.083], C1-N1 1.342(5)/1.311(5) [1.343/1.309]; C1-Si1A-Si1A' 103.67(14)/123.94 [102.16/123.51]. For 3a; Si1-Se1 2.2874(10) [2.318], Si1-Se1' 2.3046(10) [2.319], Si1-Se2 2.1510(10) [2.156]; Se1-Si1-Se1' 96.55(4) [96.52], Si1Se1-Si1' 83.45(4) [83.32], C1-Si1-Se2 97.86(11) [96.58], C1-Si1-Se1 109.85(11) [107.85], C1-Si1-Se1' 113.81(11) [113.33], Se2-Si1-Se1 119.05(4) [121.1], Se2-Si1-Se1' 120.35(4) [121.67].

bond length of 3a is 1.931 (4) $\AA$ which is close to that in 1a $(1.944$ (2) $\AA^{15 a}$ but larger than that in $2 \mathrm{a}(1.887(4) \AA$ ) (Table S1†). This suggests that the bond between carbene carbon and silicon is a donor bond $\left(\mathrm{C}_{\mathrm{cAAC}} \rightarrow \mathrm{Si}\right.$ ) (Scheme 3$)$, rather than a donoracceptor partial double bond ${ }^{9 c}$ in $\mathbf{2 a}$ as illustrated in Scheme 2. The Si1-Se1 and Si1-Se2 bond distances of 3a are 2.2874(10)/ 2.3046(10), and 2.1510(10) A, respectively, suggesting single bond (Si1-Se1, Si1-Se1') and double bond $(\mathrm{Si} 1=\mathrm{Se} 2)$ character (Scheme 3). ${ }^{\mathbf{1 4}}$ The Si1-Se1/Se1' bond distances are close to the values reported for $\left(\mathrm{SiSe}_{2}\right)_{n}$ (A) $(2.275 \AA)$. The $\mathrm{Se}-\mathrm{Si}-\mathrm{Se}$ bond angle in $\mathrm{Si}_{2} \mathrm{Se}_{2}$ four membered ring of $3 \mathrm{a}$ is $96.55(4)^{\circ}$ which is sharper $\left(\right.$ by $\sim 3.5^{\circ}$ ) than that of $\mathbf{A}\left(100.0(1)^{\circ}\right) .{ }^{3 b}$ This might be due to the coordination of $\mathrm{Me}_{2}$-cAAC to each silicon atom. The $\mathrm{Si}_{2} \mathrm{Se}_{4}$ core of compound $\mathbf{3 a}$ is structurally similar to that of (NHC) $)_{2} \mathrm{Si}_{2} \mathrm{O}_{4}$ compound reported by Robinson et al. ${ }^{\mathbf{1 2 a}}$ The silicon-silicon bond distance is $3.056 \AA$ in $3 \mathrm{a}$ while that of (NHC) $)_{2} \mathrm{Si}_{2} \mathrm{O}_{4}$ is 2.3980(11) $\AA$ which is due to the larger size of the selenium atoms.

We have performed DFT calculations to illustrate the electronic structure and bonding scenario of 3a (refer Computational Details in ESI $\dagger$ ). The optimized geometry of $\mathbf{3 a}$ at the M06-2X/SVP level shows a strong resemblance with the X-ray 
crystal structure of $3 \mathbf{a}$ (Fig. 1 and S14 $\dagger$ ). The electronic structure and bonding features of 3a are illustrated using NBO analysis as implemented in Gaussian09. The calculations reveal that $\mathrm{C} 1$ is connected to Si1 by a single bond with electron occupancy of 1.94701 e which is primarily located on the $\mathrm{C} 1(77 \%)$ center. The $\mathrm{N} 1-\mathrm{C} 1$ bond in $\mathbf{3 a}$ is significantly shorter $(1.309 \AA)$ than in $\mathbf{2 a}$ $(1.343 \AA)$ due to the strong $\pi$-bonding interaction to disrupt $\mathrm{C} 1 \leftarrow \mathrm{Si} 1$ back donation. This finding also reveals that the $\mathrm{C} 1$ is bound to the Si1 as a singlet carbene donor $(\mathrm{C} 1 \rightarrow \mathrm{Si})$. On the other hand Si1 also binds to Se2 by a single bond and Se contains three lone pairs. But the Si1-Se2 bond length is $2.15 \AA$ which is significantly shorter than the single bond length $(2.28$ $\AA$ and $2.07 \AA$ in $\mathrm{H}_{3} \mathrm{Si}-\mathrm{SeH}$ and $\mathrm{H}_{2} \mathrm{Si}=\mathrm{Se}$, respectively). It is surprising to see that the lone pair occupancies on the Se2 are $1.960,1.713$, and $1.717 \mathrm{e}$, respectively. The lowering in occupancy of the last two lone pairs can be envisaged as some sort of donor-acceptor type interaction with the Si1 atom, in turn making the bond shorter (Scheme 3).

Topological and topographical analyses are also performed for further illustration of the bonding features in 3a using QTAIM (Quantum Theory of Atoms in Molecules) calculations (see computational details in ESI†).

The electron density, $\rho(r)$, at the $(3,-1)$ bond critical points (BCPs) of C1-Si1 (0.095) and Si1-Se2 (0.104) bonds along with the respective Laplacian $\left[\nabla^{2} \rho(r) ;+0.240\right.$ and +0.051$]$ indicate closed-shell interaction i.e., donor-acceptor bond (Table S9†). This is further supported by 2D Laplacian plot of $(3,-3)$ critical points (Fig. 2, bottom). The Delocalization Index (DI) value of C1-Si1 (0.43) is lower than for an ordinary C-Si bond in $\mathrm{H}_{3} \mathrm{C}-$ $\mathrm{SiH}_{3}(0.55)$, indicating the presence of weak C1-Si1 donor type bonding. In case of the Si1-Se2 bond the DI value donor (0.6;

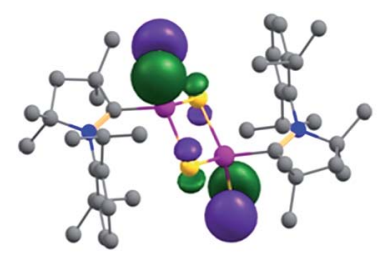

3a-HOMO

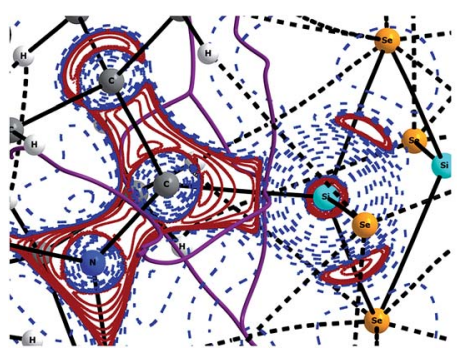

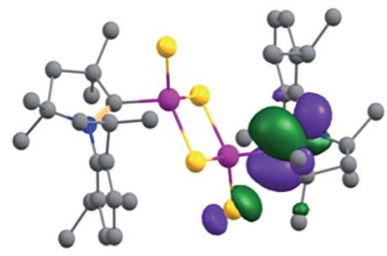

3a-LUMO

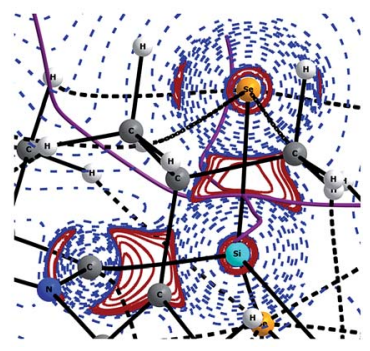

Fig. 2 (Top) Computed KS-MO of 3a at R-M06-2X/TZVP//R-M06-2X/ SVP level. Hydrogen atoms are omitted for clarity. (bottom) Laplacian distribution $\left[\nabla^{2} \rho(r)\right]$ in N1-C1-Si1 (left) and C1-Si1-Se2 plane (right) of 3a. Solid lines indicate the areas of charge concentration $\left(\nabla^{2} \rho(r)<0\right)$ while dotted lines mean the charge depletion $\left(\nabla^{2} \rho(r)>0\right)$. The range of contours of the Laplacian is $-8 \times 102$ to $+8 \times 102$. Solid lines connecting atomic nuclei (black) are the bond paths and those lines (purple) separating the atomic basins indicates the zero-flux surface crossing the molecular plane.

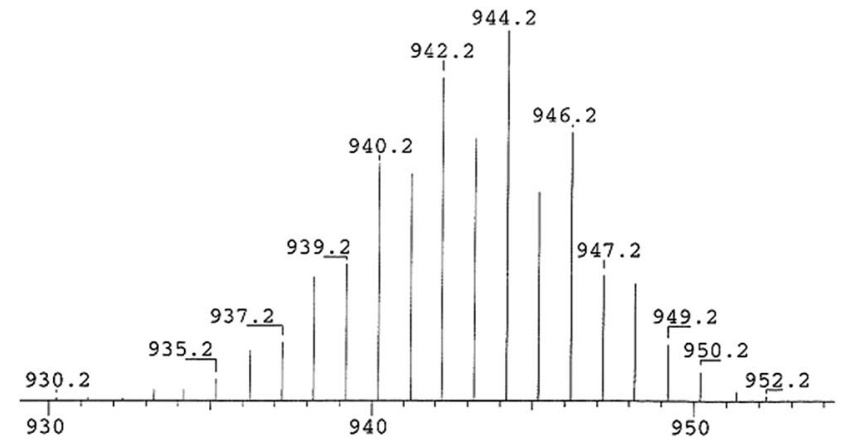

Fig. 3 (a) Experimental El-mass spectrum of compound 3a.

$\mathrm{Si} 1 \rightarrow \mathrm{Se} 2)$ is close to that of the $\mathrm{Si}-\mathrm{Se}$ single bond $(0.58)$ in $\mathrm{H}_{3} \mathrm{Si}-$ $\mathrm{SeH}$ in accordance with the NBO results discussed above. The real bonding in 3 is a combination of two resonating structures as shown in Scheme 3. In contrast the lower but positive value of Laplacian (+0.051) indicates closed-shell binding nature to lesser extent. We presume that the more electronegative Se is reluctant to share its lone pairs to the adjacent Si center in turn contributing towards equal sharing between the partners.

\section{Conclusions}

We have shown that carbene coordinated diatomic silicon(0) species $(\mathrm{cAAC})_{2} \mathrm{Si}_{2}(\mathbf{2 a - b})$ can react with black selenium powder in a $1: 4$ molar ratio in $\mathrm{THF}$ at $-78^{\circ} \mathrm{C}$ to $\mathrm{rt}$ to produce molecular compound (cAAC) ${ }_{2} \mathrm{Si}_{2} \mathrm{Se}_{4}$ (3a-b). Orange powders of $\mathbf{3 a}-\mathbf{b}$ are stable under an inert atmosphere for nearly a month and decompose above $245{ }^{\circ} \mathrm{C}$. Dark orange crystals of 3a-b retain their colors in air for a week. They are soluble in polar organic solvents, such as THF, while partially soluble in toluene and $n$ hexane. The molecular structure of 3a was confirmed by X-ray single crystal diffraction and EI-mass spectrometry (Fig. 3). A comparison between the bond parameters of 2a and 3a unambiguously led to the conclusion that the $\operatorname{Si}_{2}(0)$ unit in $2 \mathbf{a}$ is stabilized by a donor acceptor type bond between 2cAAC and (0) $\mathrm{Si}=\mathrm{Si}(0)$, while its derivative $\mathrm{Si}_{2} \mathrm{Se}_{4}$ of $\mathbf{3 a}$ has been prevented from undergoing polymerization by strong $\sigma$-donation of the cAAC molecules (Schemes 2 and 3). The bonding and stability of 3a have been further studied by theoretical calculations. To the best of our knowledge, this is the first report on a neutral ligandstabilized molecular $\mathrm{Si}_{2} \mathrm{Se}_{4}$ species. ${ }^{18,19}$

\section{Acknowledgements}

Dedicated to Professor Robert R. Holmes for his outstanding contributions in chemistry. H. W. R. thanks the Deutsche Forschungsgemeinschaft (DFG Funder ID http://dx.doi.org/ 10.13039/501100001659, RO 224/64-1) for financial support. We thank Dr. S. Demeshko for solid state UV-vis measurements. B. M. and S. D. thank CSIR, India for SRF and JRF fellowships, respectively. D. K. thanks to CSIR, India for project fund (http:// dx.doi.org/10.13039/501100001332, 01(2770)/13/EMR-II). We thank M. Tretiakov for preparing $\mathrm{Me}_{2}-\mathrm{CAAC}=\mathrm{Se}$ and $(\mathrm{NHC})_{2} \mathrm{Si}_{2}$. 


\section{Notes and references}

1 P. C. R. Sabatier, Comptes Rendus Hebdomadaires des Séances de l'Académie des Sciences, 1891, 113, 132.

2 A. Weiss and A. Weiss, Naturforschung, 1952, 7, 483.

3 (a) E. Parthé, Crystal Chemistry of Tetrahedral Structures, Gordan and Breach, New York, 1964; (b) J. Peters and B. Krebs, Acta Crystallogr., Sect. B: Struct. Crystallogr. Cryst. Chem., 1982, 38, 1270; (c) M. Celino and C. Massobrio, Phys. Rev. Lett., 2003, 90, 125502.

4 E. A. Hauschild and C. R. Kannewurf, J. Phys. Chem. Solids, 1969, 30, 353.

5 M. Tenhover, M. A. Hazle and R. K. Grasselli, Phys. Rev. Lett., 1983, 51, 404.

6 A. Pradel, V. Michel-Lledos, M. Ribes and H. Eckert, Chem. Mater., 1993, 5, 377.

7 (a) E. Mooser and W. B. Pearson, J. Electron., 1956, 1, 629; (b) D. N. Tafen and D. A. Drabold, Phys. Rev. B: Condens. Matter Mater. Phys., 2003, 68, 165208; (c) Recently came in the news of phys.org, http://phys.org/news/2014-04-material-scientistexploring-ways-efficiency.html.

8 M. N. Hopkinson, C. Richter, M. Schedler and F. Glorius, Nature, 2014, 510, 485.

9 (a) Y. Wang, Y. Xie, P. Wei, R. B. King, H. F. Schaefer III, P. V. R. Schleyer and G. H. Robinson, Science, 2008, 321, 1069; (b) Y. Xiong, S. Yao, S. Inoue, J. D. Epping and M. Driess, Angew. Chem., Int. Ed., 2013, 52, 7147; Angew. Chem., 2013, 125, 7287; (c) K. C. Mondal, P. P. Samuel, H. W. Roesky, R. R. Aysin, L. A. Leites, S. Neudeck, J. Lübben, B. Dittrich, M. Hermann and G. Frenking, J. Am. Chem. Soc., 2014, 136, 8919; (d) K. C. Mondal, H. W. Roesky, M. C. Schwarzer, G. Frenking, B. Niepötter, H. Wolf, R. Herbst-Irmer and D. Stalke, Angew. Chem., Int. Ed., 2013, 52, 2963; Angew. Chem., 2013, 125, 3036.

10 C. A. Dyker and G. Bertrand, Science, 2008, 321, 1050.

11 (a) J. D. Masuda, W. W. Schoeller, B. Donnadieu and G. Bertrand, Angew. Chem., Int. Ed., 2007, 46, 7052; Angew.
Chem., 2007, 119, 7182; (b) O. Back, G. Kuchenbeiser, B. Donnadieu and G. Bertrand, Angew., Chem. Int. Ed., 2009, 48, 5530; Angew. Chem., 2009, 121, 5638; (c) Y. Wang, Y. Xie, P. Wie, R. B. King, H. F. Schaefer III, P. V. R. Schleyer and G. H. Robinson, J. Am. Chem. Soc., 2008, 130, 14970.

12 (a) Y. Wang, M. Chen, Y. Xie, P. Wei, H. F. Schaefer III, P. V. R. Schleyer and G. H. Robinson, Nat. Chem., 2015, 7, 509-513; (b) Y. Apeloig, Nat. Chem., 2015, 7, 468-470.

13 R. Tonner, G. Heydenrych and G. Frenking, Chem.-Asian J., 2007, 2, 1555.

14 M. Y. Abraham, Y. Wang, Y. Xie, P. Wei, H. F. Schaefer, P. V. R. Schleyer and G. H. Robinson, J. Am. Chem. Soc., 2011, 133, 8874.

15 (a) K. C. Mondal, H. W. Roesky, A. C. Stückl, F. Ihret, W. Kaim, B. Dittrich, B. Maity and D. Koley, Angew. Chem., Int. Ed., 2013, 52, 11804; Angew.Chem., 2013, 125, 12020; (b) K. C. Mondal, H. W. Roesky, M. C. Schwarzer, G. Frenking, I. Tkach, H. Wolf, D. Kratzert, R. HerbstIrmer, B. Niepötter and D. Stalke, Angew. Chem., Int. Ed., 2013, 52, 1801; (c) K. C. Mondal, B. Dittrich, B. Maity, D. Koley and H. W. Roesky, J. Am. Chem. Soc., 2014, 136, 9568.

16 (a) D. Martin, M. Melaimi, M. Soleilhavoup and G. Bertrand, Organometallics, 2011, 30, 5304; (b) D. Martin, Y. Canac, V. Lavallo and G. Bertrand, J. Am. Chem. Soc., 2014, 136, 5023.

17 M. Tretiakov, Y. G. Shermolovich, A. P. Singh, P. P. Samuel, H. W. Roesky, B. Niepötter, A. Visscher and D. Stalke, Dalton Trans., 2013, 12940.

18 Lighter congener such as $\mathrm{SiS}_{2}$ and SiS were studied at low temperature in a methane matrix but not $\mathrm{SiSe}_{2}$. See M. Friesen and H. Schnöckel, Z. Anorg. Allg. Chem., 1999, 625, 1097.

19 S.-H. Zhang, H.-X. Yeong and C.-W. So, Chem.-Eur. J., 2011, 17, 3490 and all references on Si-Se compounds therein. 